\title{
Article
}

\section{The nature and function of talent identification in junior-elite football in English category one academies}

Reeves, Matthew, Littlewood, Martin, McRobert, Allistair and Roberts, Simon

Available at http://clok.uclan.ac.uk/25215/

Reeves, Matthew ORCID: 0000-0002-3903-2910, Littlewood, Martin, McRobert, Allistair and Roberts, Simon (2018) The nature and function of talent identification in junior-elite football in English category one academies. Soccer \& Society, 19 (8). pp. 1122-1134. ISSN 1466-0970

It is advisable to refer to the publisher's version if you intend to cite from the work. http://dx.doi.org/10.1080/14660970.2018.1432385

For more information about UCLan's research in this area go to http://www.uclan.ac.uk/researchgroups/ and search for < name of research Group>.

For information about Research generally at UCLan please go to http://www.uclan.ac.uk/research/

All outputs in CLoK are protected by Intellectual Property Rights law, including Copyright law. Copyright, IPR and Moral Rights for the works on this site are retained by the individual authors and/or other copyright owners. Terms and conditions for use of this material are defined in the policies page.

\section{CLoK}

Central Lancashire online Knowledge www.clok.uclan.ac.uk

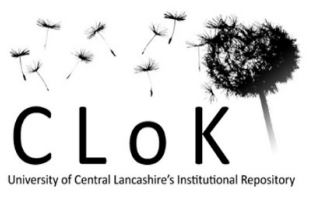


The nature and function of talent identification in junior-elite football in English category one academies

Matthew J. Reeves, ${ }^{1,2}$ Martin Littlewood, ${ }^{3}$ Allistair McRobert, ${ }^{3}$ Simon J

Roberts $^{1}$

${ }^{1}$ Sport Coaching Research Group, Liverpool John Moores University, IM Marsh

Campus, Barkhill Road, Liverpool, L17 6BD.

${ }^{2}$ Research In Sport, Liverpool, UK.

${ }^{3}$ The Football Exchange, Liverpool John Moores University, 70 Great Crosshall Street, Liverpool, $L 32 A B$.

Matthew J. Reeves

Telephone: +44(0)1512315325

m.j.reeves@ljmu.ac.uk 


\section{The nature and function of talent identification in junior-elite football in English category one academies}

The focus of this study was to examine the nature and function of talent identification in category one football academies in the UK. Data were collected from three participant groups: heads of recruitment $(n=12)$, recruitment staff $(n=18)$, and scouts $(n=7)$. Data were collected by means of semi-structured interviews, conducted either face-to-face or via Skype®. Four themes emerged from the data: 1) league structures in junior grassroots football; 2) reflective practice; 3 ) looking at the whole player; and 4) luck. The paper concludes by suggesting that there are issues that need to be considered by the football association, county football associations, and clubs. Those issues include the organisation of leagues in junior football, the education of scouts and recruitment staff around reflective practice and understanding how to identify psycho-social attributes whilst identifying talent.

Keywords: Grassroots; luck; scouting; recruitment; reflection; whole player. 


\section{Introduction}

The identification and development of talent in sport is not a new problem. It has received significant interest in the last decade or so. Across different sports the identification of talent is at the forefront of many systems, yet it is arguably one of the most difficult issues to consider: there are ever more sophisticated ways in which talent is trying to be detected, identified, and developed, meaning the state of knowledge about what may or may not be effective during the talent identification (TI) process is in constant flux. There have been doubts raised over the scientific foundations of many talent identification systems ${ }^{1}$ (Abbott, Collins, Martindale et al., 2002; Durand-Bush \& Salmela, 2001; Vaeyens, Lenoir, Williams et al., 2008) that have tended to focus on their low predictive value and validity (Durand-Bush \& Salmela, 2001; Régnier, Salmela, \& Russell, 1993). ${ }^{2}$ Despite such criticisms, however, national governing bodies of sport, clubs, and other organisations continue to heavily invest resources into the talent spotting of young children (Bailey \& Collins, 2013). ${ }^{3}$

There have been a number of approaches taken in TI in sport which, usually, focus on nature (i.e. gene-centred approaches) versus nurture (i.e. ecological and environmental approaches) (for a review, see: Davids \& Baker, 2007). ${ }^{4}$ Recently, there have been a number of football-specific studies that have started to better explore developmental factors associated with nurture (i.e. parents, Clarke \& Harwood; Clarke, Harwood \& Cushion; birthplace, Finnegan et al, 2017). ${ }^{5}$ Perhaps one of the most fertile areas of examination has been the volume and type of sport activities players have engaged in during their developmental years ${ }^{6}$ (Ford et al., 2012), which has called into question the process of early TI.

There are reasons that TI may be necessary at an early age, such as specialisation for particular sports (i.e. gymnastics). In football, however, the most common reason cited for clubs undertaking TI is to develop players for the club's first 
team (Williams \& Reilly, 2000). ${ }^{7}$ Thus, there appears a miss-match between the process of TI and the desired outcome, as previous studies suggest that early identification and specialisation. The large sums of money now attributable to player transfers in football, particularly in the highest echelons (i.e. Premier League, Bundesliga, Ligue 1, La Liga, and Serie A), means that identifying and developing indigenous talent is now considered a necessity (Carling, le Gall, Reilly \& Williams, 2009; Williams and Reilly, 2000)..$^{8}$

The job of TI within football is undertaken by a variety of people, including coaches, performance analysts, and scouts. However, at the junior-elite level, this is generally left to scouts and recruitment staff. Scouts usually report back to their respective clubs on players they have detected within grassroots football who may be suitable for the academy, that is players that a scout feels has the potential to become a professional footballer based on the needs, philosophy, and culture of their particular club. This often results in clubs tracking players over a series of games, before making a decision on whether to offer a trial, or the opportunity to sign for the club's academy. Depending upon the club, there are often networks of local, regional, national, and international scouts all scouring grassroots football for talented young players. Scouts are often considered fountains of knowledge about their 'patch': connected to local youth team managers, other scouts, and parents (Hassan, 2013). ${ }^{9}$ Historically, scouts have been responsible for much of the TI within their respective clubs and have sought players that suited the scouts' subjective image of the 'ideal' player (Williams \& Reilly, 2000). ${ }^{10}$ However, it is accepted that scouts working in isolation can result in repetitive misjudgements (Meylan et al., 2010). ${ }^{11}$ It is not just scouts operating in their subjective world that can cause problems. Numerous attempts have been made, using various methods, in either isolation or combination, to determine the most effective talent 
identification system for football (See Le Gall et al., 2010; Williams, 2000; Figueiredo et al., 2009). ${ }^{12}$

Since 2010, academies in the UK have been operating under the Premier League's Elite Player Performance Plan (EPPP) (Premier League, 2011). ${ }^{13}$ The EPPP provides a framework of operating standards that clubs are expected to adhere to in order to maintain their academy category status. It also suggests how academies might monitor and evaluate their progress and development, including their overall 'productivity'. Productivity is highlighted as "a points-based system which accurately measures the development journey of every professional player and makes it possible to measure the successful production of players at each Academy and Centre of Excellence" (Premier League, 2011; 9).

The development of academies ${ }^{15}$ (The FA, 1997) and more recently the EPPP (Premier League, 2011) ${ }^{16}$ were intended to increase the number of indigenous players within English football. Previously, a number of initiatives have been instigated that sought to bring about positive change in this regard, including: The Union of European

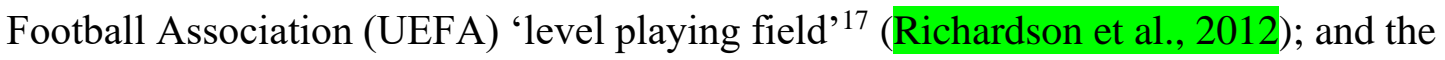
Premier League 'home grown player' rule. In both cases, the expectation was that indigenous players would be given opportunities to play at first team level in greater numbers, thus expanding the talent development (TD) pathway. However, it has been suggested that these initiatives have had little effect at increasing the number of indigenous players playing at the highest levels in the UK (Richardson et al., 2013; Premier League, 2011: 25-26). ${ }^{18}$

Despite the vast literature base associated with TI and development, there appears to be a requirement to better understand the factors associated with talent identification, one of the first steps on the pathway to, potentially, elite performance. 
Given the poor productivity of academies in the UK, it is plausible to suggest that there may be issues with TI and TD processes. To date there has been limited examination of the processes associated with identifying talented junior-elite footballers. There is still a gap in our knowledge of the processes undertaken by those responsible for identifying young talent (Christensen, 2009). ${ }^{19}$ Given what appears to be an ever-changing landscape within professional football and the race to find future first team players, it would seem pertinent to understand more. Therefore, this aims to explore the nature and function of TI in junior-elite football.

\section{Methodology}

This study was conceived to better understand the nature and function of TI processes and practice in junior-elite football. Specifically, the study was concerned with exploring the knowledge and understanding football scouts and recruitment staff operationalise during the TI process. Due to the limited literature base associated with this subject and lack of involvement of the particular participant groups, a qualitative exploratory design was chosen (Creswell, 1994). ${ }^{20}$ The benefit of an exploratory design was that it allowed the development of new areas of investigation with one of the key agents in the TI process, whilst helping to establish the priorities and foci for future studies in this space.

\section{Participants and Settings}

This study adopted non-probability purposive sampling (Patton, 2002). ${ }^{21}$ Participants were selected based on their position within a category one football academy in the UK. Specifically, participants had to be heads of recruitment, recruitment staff, or scouts. There are 21 category one football academies in the UK. Heads of recruitment were originally contacted via email $(n=16)$, or through personal 
contact where pre-existing relationships were in place $(n=5)$. All individuals contacted responded, though only 12 agreed to be involved, representing $57 \%$ of all category one academies in the UK.

Heads of recruitment were also requested to identify members of their recruitment team who may also be willing to be involved in the study. All 12 heads of recruitment responded positively and indicated the number of additional recruitment staff who were interested in being involved in the study; this ranged from one to three additional participants. These additional participants were contacted individually regarding the purpose of the study.

The final participant group for the study included heads of recruitment $(n=12)$, recruitment staff $(n=18)$, and scouts $(n=7)$. Once agreement for involvement had been confirmed, appropriate dates and times for interviews were arranged by telephone or email correspondence; this initial contact period posed an opportunity to begin to develop trust and rapport with participants ${ }^{22}$ (Sparkes and Smith, 2014), particularly those where video-based interviews were to be adopted. There was a preference to conduct interviews face-to-face interviews, though due to geographical issues and time demands this was not always possible (Deakin and Wakefield, 2014). ${ }^{23}$ However, previous studies have suggested that whilst rapport might be different, it does not affect the quality of conversation (Seitz, 2016). ${ }^{24}$ Where face-to-face interviews were not possible, Skype ${ }^{\circledR}$ interviews $(n=16)$ were arranged and conducted instead. As part of the initial contact with participants, some brief instructions were sent to try and mitigate any potential technical issues (Deakin and Wakefield, 2014). ${ }^{25}$ These instructions included: (1) Ensuring the device to be used for the interview was connected to the internet via Ethernet cable rather than over WiFi; (2) Use of an external microphone; (3) Checking the application (i.e. Skype ${ }^{\circledR}$ ) was up-to-date and any relevant updates were 
installed; (4) Ensuring any mobile devices had a full charge and/or had a charger connected; (5) Finding a quiet space where interruptions were unlikely and to help avoid inaudible segments.

All participants were male with varied experiences of working within professional and junior-elite football. Heads of recruitment had a combined working time in football of 183 years $(M=15.25$ years; \pm 4.4$)$; recruitment staff had a total time working in football of 102 years $(M=6$ years; \pm 3.7$)$; scouts had a total combined working time in football of 35 years $(M=5.8$ years; \pm 1.5$)$.

\section{Interviews}

All interviews were semi-structured, with a deductively derived interview schedule to guide topics to be covered, but allow suitable flexibility to allow examination of any arising issues (Patton, 2002). ${ }^{26}$ The interview schedule comprised two broad areas: (1) knowledge and understanding of TI; and (2) role-related considerations. Participants were also offered the opportunity to discuss any other areas or issues they felt pertinent to the aims of the study. Finally, participants were offered an opportunity to ask any questions of their own that related to the study.

All interviews were digitally recorded using a Dictaphone and transcribed verbatim. Skype® interviews were conducted on a MacBook Pro (Apple Inc., Cupertino, CA), and audio data were recorded using a Dictaphone, but also through an additional application, 'Call Recorder for Skype' (Ecamm Networks LLC, North Andover, MA). This allowed audio data to be saved directly from the original recording as well through an external device (i.e. Dictaphone). Skype® interview participants were made aware of this prior to recording beginning and consent was obtained to use the additional application. Interviews ranged in length from 47 minutes to 112 minutes (total=3116 minutes; $\mathrm{M}=89$ minutes). 


\section{Data analysis}

All data were imported into QSR NVivo 10 and subjected to a constant comparative method of analysing data (Rubin \& Rubin, 1995). ${ }^{27}$ Thus, data analysis began concurrently with data collection through a process of open and axial coding.

\section{Open coding}

Open-coding was adopted to identify concepts and their associated properties and dimensions (Strauss \& Corbin, 1998). ${ }^{28}$ This meant data were disassembled and examined during the open-coding process allowing for similarities and differences to be identified to begin developing concepts. For example, raw data extracts related to 'looking at the whole player' were brought to light during the second phase of the interview schedule, but highlighted the need to consider this issue more closely whilst analysing responses to the first phase of questions. Constant-comparative analysis began whilst data collection continued, which allowed data with similar characteristics to be grouped together, or form a new concept where an existing one did not exist. Concepts that were similar were arranged into categories and sub-categories. Descriptive labels were used to define the essential characteristics of each category and sub-category identified and aide the data characterisation process (Maykut and Morehouse, 1994).29

\section{Axial coding}

Axial coding was employed to reassemble data that had been disassembled during the open coding process (Strauss \& Corbin, 1998). ${ }^{30}$ Axial coding allowed categories, sub-categories, and concepts to be developed into more accurate descriptions of the nature and function of identifying talent in junior-elite football. Data were conceptually developed through questioning knowledge, understanding, and applied practice. 
- Players / Parents

- Quality of Coaches

- Compensation or Purchase of Players

- Quality of Scouts

- Full Time Training Model

- Players

- Parents

- Academy Staff

- Part-time Scouts

- Identity

- Efficiency vs Effectiveness

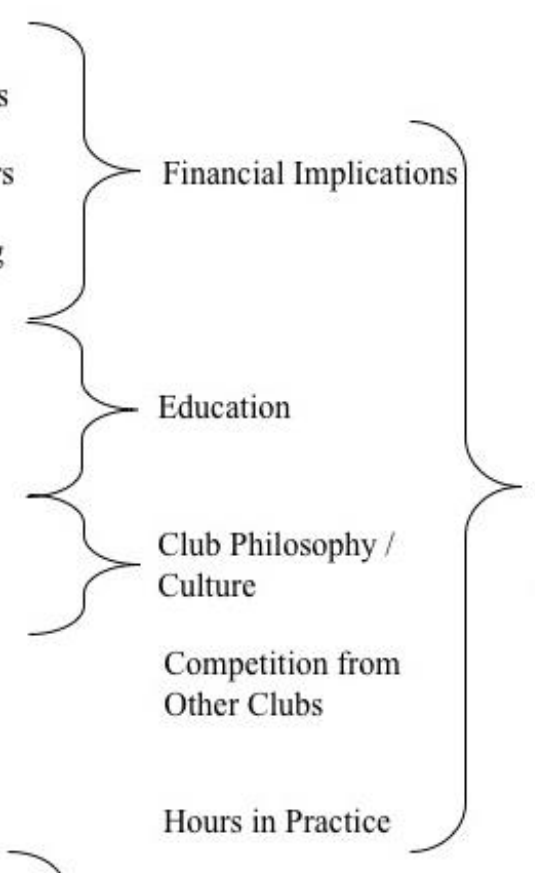

Structural Issues

- Psychological Attributes

- Family Support

- Experience of scouts

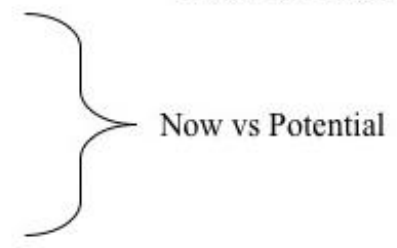

Growth, Maturation, and Development

Figure 1: Overview of the core themes, categories, and sub-categories pertaining to the nature and function of talent identification in junior-elite football.

\section{Findings and Discussion}

Inductive analysis and verification resulted in five core themes associated with the nature and function of identifying talent in junior-elite football: (1) League structures in junior grassroots football; (2) Reflective practice; (3) Looking at the whole player; and (4) Luck. These core themes and associated categories are presented in Figure 1. The following section considers the factors inductively derived and compares and integrates existing research literature. 


\section{League structures in grassroots football}

Grassroots football is a key area for talent identification: it is where clubs look for talented youngsters to invite to pre-academies, for trial, or to ultimately sign as a junior player. There were reported differences between different county football associations (CFAs) and how well they appeared to operate and run grassroots leagues.

"Great Westshire has a brilliant league set up. Well organised, well run, plenty of teams and competition. You head to Hogsmeadeshire and it's the polar opposite. Shite leagues - loads of them but only five or six teams in a league, for fucks sake. How is that of value to anyone?" (Recruitment staff 3 )

Given that academies, particularly category one academies, are able to scour junior leagues on a national scale, participants were able to draw on significant experience of leagues around the country. The perceived issues associated with league structures were different depending on the CFA leagues were affiliated to. This was further complicated by the varied size, shape, and demographics of the counties across England. There are no prior studies that have considered the operational effectiveness of CFA or the efficacy of grassroots league structures, and certainly none that have considered the impact this may have upon TI.

\footnotetext{
"The leagues near us are a bit of mixed bag. Some good, some bad, some ugly. I think they've got a tough job in some ways as there aren't as many kids playing as there used to be, I think the leagues have got smaller but rather than collapsing them they've kept the same number they've always had.” (Scout 2)
}

There were suggestions that a downturn in participation may have affected the number of clubs able to field a team in each respective league. The national landscape for grassroots football participation in England is one of decline with data suggesting that participation in grassroots football has significantly decreased since $2007^{31}$ (Sport 
England, 2016), suggesting a possible downturn in the overall size of the talent pool, though it was not possible to isolate data to particular age groups.

Downturn in participation may, indeed, have affected the number of teams participating in a single league structure, but the responsibility for overseeing the number of leagues lies with CFAs. Thus, a lack of strategic operation within CFAs may have led to disproportionate numbers of leagues to the number of teams able and willing to play. This study, through its exploratory design, has highlighted some potential shortcomings in the organisation of grassroots football, such as the dilution of meaningful competition through superfluous numbers of leagues, perhaps leading to lesser development of junior players within the grassroots system. This has clear implications for TI within football, as the main identification environment for academies.

\section{Looking where others don't}

Participants in this study highlighted the importance of looking where others don't. This idea followed a sequence of knowing, understanding, and expecting others to be looking in the 'usual' places for potentially talented players.

"We know that the best leagues are full of the biggest, strongest, fastest kids. But they're not necessarily going to be the ones who make it, are they? There are loads of kids who maybe haven't developed quite as much who are technically good, just missing the physical stuff that will come later...these kids are usually is weaker or lower leagues...we try getting scouts to look there, but a lot of them are fixed in their thinking of where talent will be playing." (Head of recruitment 7)

"Looking at different leagues, not just where the best lads are is important. That's been a hard sell to some scouts, though. They can't understand why they're being asked to watch a division five game when there's division one or two games going on ... that's been tough." (Recruitment staff 11) 
Participants suggested that the outcome-orientated league structure of junior football means that the relative age effect (RAE) becomes a significant issue (Vaeyens, Philippaerts and Malia, 2005). ${ }^{32}$ Clubs, managers, and parents reinforce the need for junior teams to win and, thus, the requirement is for teams to have players that are able to impact games. This draws grassroots clubs toward players who appear better able players and these players often make up a large percentage of the upper echelons of junior grassroots leagues.

The RAE issue was noted as one that was easy to overcome in theory, but was more difficult in practice. There appeared to be a tendency for recruitment staff and scouts to still focus their efforts on higher grassroots league divisions, that is leagues comprised of players whom tend to be early births and, thus, demonstrating higher levels of current performance. However, there were also reported efforts being made to affect positive change and ensure scouts were looking in more varied leagues than the best (i.e. highest divisions) in junior football. Examples of players that have taken nontraditional talent development pathways were used by participants to highlight and rationalise the importance of not trying to identify talent 'where it might be expected' (Scout 1).

“...you've only got to look at the likes of Jamie Vardy to see exactly why we should be looking outside of the box..." (Recruitment staff 18)

"There are lots of high profile players at the moment who weren't found in the most obvious places, or went in and out of the system before finally being picked up." (Scout 2)

The notion of looking for talent in different places is not new. Talent transfer programmes have been used across various sports for a number of years (Collins, Collins, MacNamara and Jones, 2014). ${ }^{33}$ Football, however, has always been a popular, 
if not the most popular, sport in the UK which has meant a larger-than-average talent pool when compared to other sports. The examples provided by participants, of players that have taken non-linear pathways did not move outside of football, in all cases players moved between levels of participation and competition, but not out of the sport. There are no studies to date, that have explicitly examined non-linear talent development pathways in football.

Internal structural issues within clubs were highlighted as prohibitive in enabling TI staff to look where others don't. For example, participants suggested that their clubs' community departments had access to large samples of potential talent through their outreach activity, but that there was no connectivity between the TI department and the community department.

"Stupidly, there's no joined-up thinking. The community side don't speak to us, and we don't speak to them. We used to, but don't anymore. It's stupid. They're seeing thousands of school kids every year but we don't have any way for them to input what they see to the recruitment department." (Head of recruitment 1)

“...we could have excellent coverage if we worked closer with other departments in the club, but it doesn't happen. We've got one of, well I think, one of the best outreach programmes in the country that is embedded across the city yet we don't try to use it to help us find talented players...it's been mentioned for a long time, but nothing happens.” (Recruitment staff 18)

Such issues, potentially, inhibited TI departments/staff from being more efficient. However, it could be contended that many clubs operate community activity for altruistic purposes and not to directly benefit the club as an additional means for identifying talent. This may be a situation all clubs need to consider and it may be the philosophies of the respective departments (i.e. recruitment and community) that do not align and, thus, restrict TI being undertaken as part of the community-based activities. 


\section{Reflective practice}

All participants made reference to undertaking a form of reflective practice. This focussed on personal and professional experience, specifically related to youngsters who had made it through the system when it looked as though they wouldn't, and those who didn't make it when it appeared they might become exceptional professionals.

“There's one's you get right and there's one's you get wrong. The one's you get right are brilliant, because they reinforce that what you're doing is right. The one's you get wrong are where you learn. They're where you have to go away and think long and hard ... from the first time you seen them to the last ... what happened? What might have changed? Should you have seen it coming? You know, they're the ones that make you think." (Scout 4)

“You just think back to the boys who've made it, they're your yard stick for what the next players you're looking for will look like. There's s a range of experience that comes into it...for me, running a junior team is where it started and I still use what I learned then to help me now." (Scout 1)

Participants highlighted the importance of reflecting on practice; that is, looking back at events and making sense of practice to inform and, hopefully, improve future action (Gilbert \& Trudel, 2005). ${ }^{34}$

"The more you do this, the more you have to think. There is a lot of experience that gets built up and you have to constantly be thinking back to what you've seen before to try and make better decisions in the future." (Scout 2)

"It's experience, it's looking at what you've seen before and using that to help make decisions now." (Head of recruitment 14)

Interestingly, participants were happy to regale their various successes and how players that 'they' had identified had 'made it' and how this had affected what and how they operated in practice. However, those who did not make it were not often 
discussed. Reflective practice is often represented as experiential learning, as opposed to in depth analysis of practice (Leitch \& Day, 2000). ${ }^{35}$ There are suggestions that adopting a type of reflection that links retrospection and review to projection, as appeared to be happening in this study, which is more akin to performance evaluation, fails to capture and consider implications of the proposed actions arising from the reflections (Cropley et al., 2015; Dixon, Lee \& Ghaye, 2013). ${ }^{36}$

Interestingly, the narratives created and value attributed, by and amongst participants, helped generate a sense of social meaning (Sparkes, 2005) ${ }^{37}$ Narratives become a form of legitimacy and currency, used by individuals to reinforce their value and abilities. As a narrative becomes more established, inter-related and more meaningful it might reinforce the subjective nature of TI in junior football and proliferates the repetitive misjudgements that can be made ${ }^{38}$ (Meylan et al., 2010), especially when such narratives only focus on the successes and not the failures of individuals involved in TI. This might then manifest within some organisations cultures, where it becomes framed as having a "common language and conceptual categories" (Schien, 2010: 94). ${ }^{39}$ Indeed, these narratives appeared to be the common standard for how those working within junior-elite football communicated knowledge, understanding, reality, and fact (Schein, 2010: 95). ${ }^{40}$

It could be argued that although unstructured, the fact that reflection was occurring at all, is positive. Indeed, drawing on the extant literature from sport coaching, studies have supported the notion of reflective practice aiding learning and development (Irwin, Hanton \& Kerwin, 2004). ${ }^{41}$ Reflective practice in this study, however, appeared to be largely informal and varied amongst participants.

The idea of reflecting on-action multiple times offers an opportunity to revisit experiences in order to consider practice, context, and self and their symbiotic 
relationship (Cropley et al., 2015). ${ }^{42}$ Most commonly, participants referenced their 'internal database' of players at particular ages and stages of development (Christensen, 2009). ${ }^{43}$ Yet studies have suggested memory decay ${ }^{44}$ (Nicholls \& Polman, 2008) and personal biases $^{45}$ (Bahrick, Hall \& Berger, 1996) can impact this type of reflective process. Thus, there appeared to be a need for clubs to better formalise reflective activity amongst recruitment staff and scouts. Indeed, whilst some reflection on-action was occurring, the approaches adopted may be less effective than if clubs developed and delivered structured learning and development opportunities that encompassed reflective practice specifically for recruitment staff and scouts, particularly those who operate in a part-time or voluntary capacity.

\section{Looking at the whole player}

All respondents discussed the idea of looking at the whole player, though when probed for more on what this meant, responses became vague. There were instances where respondents identified what this meant to them, or their club, though many were largely unsure.

\footnotetext{
"We know what we want, we know what we're looking for...pretty clearly now, actually...It's definitely important to look at the whole player, there is so much going on in young lads lives these days, you have to think about more than just football-related stuff." (Head of recruitment, 4)
}

"Well, we try and have a relationship that goes beyond the club...the full-time model [Full time education model, see Premier League, 2011] helps manage things with school more efficiently when we have the boys signed, but before that it's a full-time job for someone to keep on top of those we're showing interest in...sometimes we just can't, it becomes a missing piece of the jigsaw at that moment in time." (Recruitment staff 16) 
Data suggest that looking at the whole player meant considering factors that could affect performance and development of junior-elite footballers, which went beyond physical, physiological, technical, and tactical abilities (Miller, Cronin \& Baker, 2015). ${ }^{46}$ However, whilst players are in the process of being identified, being able to access some of these data sources may be problematic. This raises issues of how effectively TI can consider psycho-social factors that may affect performance and development.

"I think over the last 5 years or so we have become more understanding of the psychological and social factors that might affect players and how we need to try to identify these as soon as possible to pick up on any negative ones and do something, if we can...that's a big ask for scouts at the minute, though, I don't think we have it cracked yet." (Recruitment staff 5)

The consideration of viewing players holistically has been posited as more effective than considering talent through gene-centred methods (Bouchard \& Hoffman, 2011; Montgomery \& Safari, 2007) ${ }^{47}$ ecological or environmentalist approaches ${ }^{48}$ (Ericsson et al., 1993, 2006), with the need for multi-dimensional models of TI now considered most appropriate (Baker, 2003, 2007; Phillips et al., 2010; Vaeyens et al., 2008). ${ }^{49}$ Indeed, there is a particular emphasis in the contemporary TI literature that the psycho-social factors within elite sport and, specifically, football have been cited as important to better understand (MacNamara \& Collins, 2013). ${ }^{50}$ Whilst it is now widely accepted that elite athletes have a robust and multi-faceted psychological profile (Durand-Buh \& Samela, 2002; Fletcher \& Sakar, 2012), ${ }^{51}$ there have been no investigations to explore how psychological profiling might be utilised during the TI process in junior football. Arguably, the process of identifying junior footballers' psychological traits could become another subjective issue, as rigorous psychological assessments, by none qualified individuals, might be difficult to conduct in the context 
and environment that scouts and recruitment staff operate. However, it may be possible for psychologists to help develop a set of psychological attributes and traits for recruitment staff and scouts to consider when identifying talent that also encompasses the broader club player development philosophy.

Some studies have previously focussed on TI as a static phenomenon (Miller et al., 2015: 653).$^{52}$ However, the idea that it is more reflexively aligned to a long-term development process is not novel (Vaeyens et al., 2008; van Rossum \& Gagne, 2005). ${ }^{53}$ Where some have suggested that there may be a closer alignment of TI and TD, we contend that the closeness only comes once a player is within a TD programme (i.e. signed to a club). Before this point, TI is conducted by individuals who have little input into a player's development programme late in time. This means that regardless of the proximity, there is still a time, albeit sometimes short, where TI is still a unique, standalone process. That does not mean the process is static, rather that it should not be seen as so close to TD as to not be discernible.

It appears that there may still be considerable work to be done when considering the factors that affect the whole player from a TI perspective. There has, historically, been a tendency to consider physiologically-affected attributes, though an apparent shift appears to be taking place, whereby psycho-social factors that affect development and performance are also being considered, though the efficacy of this is still in its relative infancy.

\section{Luck}

One of the most commonly recurring issues from respondents was luck. It was used to reference identifying players, players making the transition to professional, and even participants' employment status. There appeared to be no area that could not be affected, in some way, by luck. 
“There have been lads I've come across, not huge names, but I'd say they were pretty lucky to get where they have." (Scout, 6)

"I'd say $90 \%$ of this is about luck. If you think about the number of factors that have to fall in place for a boy to firstly get spotted, get kept on for a number of years, make the transition to the first team, get a chance in the first team - you can't tell me there isn't a certain amount of luck in there, somewhere." (Head of recruitment 9)

Luck in sport has had very little academic interest outside of the philosophical sphere. Whilst there are undoubtedly studies that have highlighted, such as this one has, that luck is considered to play a role in various aspects of performance, recovery, development, or any combination of the multitude of facets it may be perceived to impact upon. However, luck is a complex phenomenon with numerous typologies proposed (Bailey, 2007). ${ }^{54}$ Thus, defining what luck actually is, is difficult; which makes it hard to "distinguish its operation from that of other factors at work in human affairs" (Rescher, 2015: 169). ${ }^{55}$

Much of the recent work on the philosophy of luck $^{56}$ (Coffman, 2005; Ballantyne, 2011; Levy, 2011) has considered luck as a relationship between an event and a subject. However, it has been suggested that understanding luck will not help to understand knowledge or Gettier problems (Milburn, 2011). ${ }^{57}$ Therefore, philosophically, luck may fail to hold much significance (Ballantyne, 2011) ${ }^{58}$ whilst in a research and practical sense, it could be argued we need to better understand and unpack the underlying assumptions of what luck is and means in junior-elite football and whether it can be considered in a different way; one that has directly locatable, measurable, and/or traceable features to why things are considered luck within the context of junior-elite football. 
If, as Rescher suggests "Luck is a matter of having something good or bad happen that lies outside the horizon of effective foreseeability...Y You are fortunate if something good happens to you or for you in the natural course of things" (1995: p. 28), ${ }^{59}$ then a junior footballer being identified as talented is not lucky, as one might reasonably expect a scout to be watching a junior football game, meaning that the potential outcome of being identified was fortunate as opposed to lucky. In other words, being a junior footballer, playing in a junior league, where scouts look to identify potential talent lies within the horizon of foreseeability and cannot be considered luck. Therefore, the notion of luck within TI in junior-elite football is, we suggest, a misdirection, or a mask, of the real issues that are at the heart of the issue or outcome posited as lucky.

\section{Conclusion}

This study sought to explore the nature and function of TI processes and practice in junior-elite football, with a particular focus on understanding the phenomenon from the perspective of those responsible for undertaking the activity. Analysis of 37 interviews with TI professionals within junior-elite football highlighted four key themes that have been discussed above.

There appeared to be a range of geographical issues, from high concentrations of professional clubs in particular areas to the organisation of league structures within county FAs and the impact these had upon clubs' abilities to operate TI effectively. This had subsequent issues around where might be the best place to look for potential talent. We suggest that there needs to be examination of the league structures in junior football in the UK, in order to better understand issues which may affect the organisation and operation of junior football leagues. 
Reflection on practice was clearly occurring amongst the participants in this study. However, all of the participants reported that this was largely unstructured and happening subconsciously. It would appear to be beneficial for clubs to consider supporting and educating scouts and recruitment staff on the use of reflective practice to enhance their personal practice and also attend to issues of consistency in their TI decision-making.

Respondents highlighted the importance of seeing beyond the immediacy of physical determinants of talent and considering players more holistically, with a particular focus on trying to explore the psycho-social aspects of performance within their identification assessments. Determining the psycho-social attributes players are expected to demonstrate, we suggest, is something that requires input from appropriately trained staff (i.e. psychologists) and takes into consideration factors such as the club's player development philosophy and culture. 


\section{Notes}

1. Abbott et al. 'Talent identification and development'; Durand-Bush and Salmela, 'The development and maintenance'; Vaeyens et al., 'Talent identification and development'.

2. Durand-Bush and Salmela, 'The development and maintenance'; Régnier, Salmela, and Russell, 'Talent detection and development'.

3. Bailey and Collins, 'The problem with the pyramid'.

4. For a review, see: Davids \& Baker, 'Genes, environment and sport performance'.

5. Clarke and Harwood, 'Parenting experiences in elite youth football'; Clarke, Harwood and Cushion, 'A phenomenological interpretation of the parent-child relationship'; Finnegan et al., 'The influence of date and place of birth'.

6. Ford et al., 'The developmental activities of elite soccer players'.

7. Williams and Reilly, 'Talent identification and development in soccer'.

8. Carling et al., 'Do anthropometric and fitness characteristics vary'; Williams and Reilly, 'Talent identification and development in soccer'.

9. Hassan, 'Searching for the next Lionel Messi'.

10. Williams and Reilly, 'Talent identification and development in soccer'.

11. Meylan et al., 'Talent Identification in Soccer'.

12. See le Gall et al., 'Anthropometric and fitness characteristics'; Williams, 'Perceptual skill in soccer'; Figueiredo et al., 'Youth soccer players'.

13. Premier League, 'Elite player performance plan'.

\section{Ibid, 9.}

15. The Football Association Technical Department, 'Football Education for Young Players'.

16. Premier League, 'Elite player performance plan'.

17. Richardson et al., 'An Examination of the Migratory Transition of Elite Young European Football Players'.

18. Premier League, 'Elite player performance plan', 25-26; Richardson et al., 'Sociological and Cultural Influences on Player Development'.

19. Christensen, “"An eye for talent”.

20. Creswell, Research design.

\section{Patton, Qualitative research \& evaluation methods.}

22. Sparkes and Smith, Qualitative research methods in sport, exercise and health. 


\section{Deakin and Wakefield, 'Skype interviewing'.}

24. Seitz, 'Pixilated partnerships, overcoming obstacles in qualitative interviews'.

25. Deakin and Wakefield, 'Skype interviewing'.

\section{Patton, Qualitative research \& evaluation methods.}

27. Rubin and Rubin, Qualitative interviewing: The art of hearing data.

\section{Strauss and Corbin, Basics of qualitative research.}

29. Maykut and Morehouse, Beginning qualitative research: A philosophical and practical guide.

\section{Strauss and Corbin, Basics of qualitative research.}

\section{Sport England, Active People Survey.}

32. Vaeyens, Philippaerts and Malina, 'The relative age effect in soccer'.

\section{Collins et al., 'Change of plans'.}

34. Gilbert and Trudel, 'Learning to Coach through Experience'.

35. Leitch and Day, 'Action research and reflective practice'.

36. Cropley et al., 'Learning to learn: The coach as a reflective practitioner'; Dixon, Lee and Ghaye, 'Reflective practices for better sports coaches and coach education'.

37. Sparkes, 'Narrative analysis'.

38. Meylan et al., 'Talent Identification in Soccer'.

39. Schien, 'Assumptions about managing internal integration', 94.

40. Ibid., 95 .

41. Irwin, Hanton and Kerwin, 'Reflective practice and the origins of elite coaching knowledge'.

42. Cropley et al., 'Learning to learn: The coach as a reflective practitioner'.

43. Christensen, “"An eye for talent”".

44. Nicholls and Polman, 'Think aloud: acute stress and coping strategies during golf performances'.

\section{Bahrick, Hall and Berger, 'Accuracy and Distortion in Memory'.}

46. Miller, Cronin and Baker, 'Nurture, nature and some very dubious social skills'.

47. Bouchard and Hoffman, 'Genetic and molecular aspects of sports performance'; Montgomery and Safari, 'Genetic basis of physical fitness'. 
48. Ericsson, Krampe and Tesch-Römer, 'The role of deliberate practice in the acquisition of expert performance'; Ericsson et al, The Cambridge Handbook of Expertise and Expert Performance.

49. Baker, 'Nature and nurture interact to create expert performers'; Baker et al., 'Nurturing Sport Expertise'; Phillips et al., 'Expert performance in sport and the dynamics of talent development'; Vaeyens et al., 'Talent identification and development'.

50. MacNamara and Collins, 'More of the same?'.

51. Durand-Bush and Salmela, 'The development and maintenance'; Fletchr and Sakar, 'A grounded theory of psychological resilience'.

52. Miller, Cronin and Baker, 'Nurture, nature and some very dubious social skills', 653.

53. Vaeyens et al., 'Talent identification and development'; van Rossum and Gange, Talent development in sports.

54. Bailey, 'Talent development and the luck problem'.

55. Rescher, 'The machinations of luck', 169.

56. Coffman, 'Thinking about luck’; Ballantyne, ‘Anti-luck epistemology’; Levy, Hard luck.

57. Milburn, 'Subject-involving luck'.

58. Ballantyne, 'Anti-luck epistemology'.

59. Rescher, Luck: The brilliant randomness of everyday life, 28. 


\section{References}

Abbott, Angela, Dave Collins, Russell J.J. Martindale, and Katie Sowerby. Talent Identification and Development: An Academic Review. Edinburgh: Sport Scotland, 2002.

Bahrick, Harry P., Lynda K. Hall, and Stephanie A. Berger. “Accuracy and Distortion in Memory for High School Grades.” Psychological Science 7, no. 5 (1996): 265-71. doi:10.1111/j.1467-9280.1996.tb00372.x.

Bailey, Richard. "Talent Development and the Luck Problem." Sport, Ethics and Philosophy 1, no. 3 (2007): 367-77. doi:10.1080/17511320701676999.

Bailey, Richard, and Dave Collins. "The Problem with the Pyramid: Why Most Models of Talent Development Are Flawed." In Elite Sport and Sport-for-All: Bridging the Two Cultures?, edited by Richard Bailey and Margaret Talbot, 72-84. London: Routledge, 2015.

Baker, Joseph, Sean Horton, Jennifer Robertson-Wilson, and Michael Wall. "Nurturing Sport Expertise: Factors Influencing the Development of Elite Athlete.” Journal of Sports Science \& Medicine 2, no. 1 (2003): 1-9.

Ballantyne, Nathan. “Anti-Luck Epistemology, Pragmatic Encroachment, and True Belief." Canadian Journal of Philosophy 41, no. 4 (2011): 485-503. doi:10.1353/cjp.2011.0041.

Bouchard, Claude, and Eric P. Hoffman. "Genetic and Molecular Aspects of Sports Performance." The Encyclopaedia of Sports Medicine: An IOC Medical Commission Publication, Volume XVIII,. Wiley-Blackwell, 2011.

Carling, Chris, Franck Le Gall, Tom Reilly, and A. Mark Williams. "Do Anthropometric and Fitness Characteristics Vary according to Birth Date Distribution in Elite Youth Academy Soccer Players?" Scandinavian Journal of Medicine \& Science in Sports 19, no. 1 (2009): 3-9. doi:10.1111/j.16000838.2008.00867.x.

Christensen, Mette Krogh. “'An Eye for Talent': Talent Identification and the 'practical Sense' of Top-Level Soccer Coaches.” Sociology of Sport 26, no. 3 (2009): 36582.

Clarke, Nicola J., and Chris G. Harwood. "Parenting Experiences in Elite Youth Football: A Phenomenological Study." Psychology of Sport and Exercise 15, no. 5 (2014): 528-37. doi:10.1016/j.psychsport.2014.05.004. 
Clarke, Nicola J., Chris G. Harwood, and Chris J. Cushion. “A Phenomenological Interpretation of the Parent-Child Relationship in Elite Youth Football." Sport, Exercise, and Performance Psychology 5, no. 2 (2016): 125-43. doi:10.1037/spy0000052.

Coffman, E. J. “Thinking about Luck.” Synthese 158, no. 3 (2007): 385-98. doi:10.1007/s11229-006-9046-8.

Collins, Rosie, Dave Collins, Áine MacNamara, and Martin Ian Jones. “Change of Plans: An Evaluation of the Effectiveness and Underlying Mechanisms of Successful Talent Transfer.” Journal of Sports Sciences 32, no. 17 (2014): 1621-30. doi:10.1080/02640414.2014.908324.

Creswell, John W. Research Design: Qualitative and Quantitative Approaches. London: Sage, 1994.

Cropley, Brendan, Andy Miles, and Toby Nichols. "Learning to Learn: The Coach as a Reflective Practitioner.” In Becoming a Sports Coach, edited by James Wallis and John Lambert, 11-26. London: Routledge, 2015.

Davids, Keith, and Joseph Baker. "Genes, Environment and Sport Performance: Why the Nature-Nurture Dualism Is No Longer Relevant.” Sports Medicine 37, no. 11 (2007): 961-80. doi:10.2165/00007256-200737110-00004.

Deakin, Hannah, and Kelly Wakefield. "Skype Interviewing: Reflections of Two PhD Researchers." Qualitative Research 14, no. 5 (2014): 603-16. doi:10.1177/1468794113488126.

Dixon, Martin, Sarah Lee, and Tony Ghaye. "Reflective Practices for Better Sports Coaches and Coach Education: Shifting from a Pedagogy of Scarcity to Abundance in the Run-up to Rio 2016." Reflective Practice 14, no. 5 (2013): 585-99. doi:10.1080/14623943.2013.840573.

Durand-Bush, Natalie, and John H. Salmela. "The Development and Maintenance of Expert Athletic Performance: Perceptions of World and Olympic Champions." Journal of Applied Sport Psychology 14, no. 3 (2002): 154-71. doi:10.1080/10413200290103473.

Ericsson, K Anders, Ralf Th. Krampe, and Clemens Tesch-Römer. "The Role of Deliberate Practice in the Acquisition of Expert Performance." Psychological Review 100, no. 3 (1993): 363-406. doi:10.1037//0033-295X.100.3.363. 
Ericsson, K. Anders, Neil Charness, Paul J. Feltovich, and Robert R. Hoffman, eds. The Cambridge Handbook of Expertise and Expert Performance. Cambridge: Cambridge University Press, 2006.

Figueiredo, António J., Carlos E. Gonçalves, Manuel J Coelho E Silva, and Robert M Malina. "Youth Soccer Players, 11-14 Years: Maturity, Size, Function, Skill and Goal Orientation.” Annals of Human Biology 36, no. 1 (2009): 60-73. doi:10.1080/03014460802570584.

Finnegan, Laura, David Richardson, Martin Littlewood, and Jean McArdle. "The Influence of Date and Place of Birth on Youth Player Selection to a National Football Association Elite Development Programme." Science \& Medicine in Football 1, no. 1 (2017): 30-39. doi:10.1080/02640414.2016.1254807.

Fletcher, David, and Mustafa Sarkar. "A Grounded Theory of Psychological Resilience in Olympic Champions." Psychology of Sport and Exercise 13, no. 5 (2012): 669-78. doi:10.1016/j.psychsport.2012.04.007.

Ford, Paul R., Christopher Carling, Marco Garces, Mauricio Marques, Carlos Miguel, Andrew Farrant, Andreas Stenling, et al. "The Developmental Activities of Elite Soccer Players Aged under-16 Years from Brazil, England, France, Ghana, Mexico, Portugal and Sweden.” Journal of Sports Sciences 30, no. 15 (2012): 1653-63. doi:10.1080/02640414.2012.701762.

Gilbert, Wade D, and Pierre Trudel. "Learning to Coach through Experience: Conditions That Influence Reflection.” Physical Educator 62, no. 1 (2005): 3243.

Hassan, Nabil. "Searching for the next Lionel Messi: The Life of a Football Scout." BBC Sport, 2013. http://www.bbc.co.uk/sport/football/24653124.

Irwin, Gareth, Sheldon Hanton, and David Kerwin. "Reflective Practice and the Origins of Elite Coaching Knowledge.” Reflective Practice 5, no. 3 (2004): 425-42. doi:10.1080/1462394042000270718.

le Gall, Franck, Chris Carling, A. Mark Williams, and Tom Reilly. “Anthropometric and Fitness Characteristics of International, Professional and Amateur Male Graduate Soccer Players from an Elite Youth Academy.” Journal of Science and Medicine in Sport 13, no. 1 (2010): 90-95.

Leitch, Ruth, and Christopher Day. "Action Research and Reflective Practice: Towards a Holistic View." Educational Action Research 8, no. 1 (2000): 179-93. doi:10.1080/09650790000200108. 
Levy, Neil. Hard Luck: How Luck Undermines Free Will and Moral Responsibility.

Oxford: Oxford University Press, 2011.

MacNamara, Aine, and Dave Collins. "More of the Same? Comment on 'An Integrated

Framework for the Optimisation of Sport and Athlete Development: A

Practitioner Approach."” Journal of Sports Sciences 32, no. 8 (2014): 793-95.

doi:10.1080/02640414.2013.855805.

Maykut, Pamela, and Richard Morehouse. Beginning Qualitative Research: A

Philosophical and Practical Guide. Lewes, UK: Falmer Press, 1994.

Meylan, Cesar, John Cronin, Jon Oliver, and Michael Hughes. "Talent Identification in

Soccer: The Role of Maturity Status on Physical, Physiological and Technical

Characteristics.” International Journal of Sports Science and Coaching 5, no. 4 (2010): 571-92.

Milburn, Joe. "Subject-Involving Luck." In The Philosophy of Luck, edited by Duncan Pritchard and Lee John Whittington, 127-42. Chichester: Wiley-Blackwell, 2011.

Miller, Paul K., Colum Cronin, and Graham Baker. "Nurture, Nature and Some Very Dubious Social Skills: An Interpretative Phenomenological Analysis of Talent Identification Practices in Elite English Youth Soccer." Qualitative Research in Sport, Exercise, and Health 7, no. 5 (2015): 642-62.

doi:10.1080/2159676X.2015.1012544.

Montgomery, Hugh, and Latif Safari. "Genetic Basis of Physical Fitness." Annual

Review of Anthropology 36, no. 1 (2007): 391-405.

doi:10.1146/annurev.anthro.36.081406.094333.

Nicholls, Adam R., and Remco C. J. Polman. "Think Aloud: Acute Stress and Coping Strategies during Golf Performances.” Anxiety, Stress \& Coping 21, no. 3 (2008): 283-94. doi:10.1080/10615800701609207.

Patton, Michael Q. Qualitative Research \& Evaluation Methods. 3rd ed. London: Sage, 2002.

Phillips, Elissa, Keith Davids, Ian Renshaw, and Marc Portus. "Expert Performance in Sport and the Dynamics of Talent Development." Sports Medicine 40, no. 4 (2010): 271-83. doi:10.2165/11319430-000000000-00000.

Premier League. “Elite Player Performance Plan.” London, 2011.

Régnier, Guy, John Salmela, and Storm J. Russell. "Talent Detection and Development in Sport." In Handbook on Research on Sport Psychology, edited by Robert N. 
Singer, Milledge Murphey, and L. Keith Tennant, 290-313. New York: Macmillan, 1993.

Rescher, Nicholas. "The Machinations of Luck." In The Philosophy of Luck, edited by Duncan Pritchard and Lee John Whittington, 169-76. Chichester: WileyBlackwell, 2015.

Rescher, Nicholas. Luck: The Brilliant Randomness of Everyday Life. Pittsburgh, PA: University of Pittsburgh Press, 1995.

Richardson, Dave, Martin Littlewood, Mark Nesti, and Luke Benstead. “An Examination of the Migratory Transition of Elite Young European Football Players to the English Premier League.” Journal of Sports Sciences 30, no. 15 (2012): 1605-18.

Richardson, David, Hugo Relvas, and Martin Littlewood. "Sociological and Cultural Influences on Player Development.” In Science and Soccer: Developing Elite Performers, edited by A. Mark Williams, 3rd ed., 139-53. London: Routledge, 2013.

Rubin, Herbert J, and Irene S Rubin. Qualitative Interviewing: The Art of Hearing Data. London: Sage, 1995.

Schein, Edger H. “Assumptions about Managing Internal Integration.” In Organizational Culture and Leadership, 4th ed., 93-113. Chichester: John Wiley \& Sons, 2010.

Seitz, Sally. "Pixilated Partnerships, Overcoming Obstacles in Qualitative Interviews via Skype: A Research Note.” Qualitative Research 16, no. 2 (2016): 229-35. doi:10.1177/1468794115577011.

Sparkes, Andrew C., and Brett Smith. Qualitative Research Methods in Sport, Exercise and Health: From Process to Product. Oxon: Routledge, 2014.

Sparkes, Andrew Clive. "Narrative Analysis: Exploring the Whats and the Hows of Personal Stories.” In Qualitative Research in Health Care, edited by Immy Holloway, 191-209. Maidenhead: Open University Press, 2005.

Sport England. “Active People Survey.” Active People Survey 10, 2016. https://www.sportengland.org/research/about-our-research/active-peoplesurvey/.

Strauss, Anselm, and Juliet M. Corbin. Basics of Qualitative Research: Techniques and Procedures for Developing Grounded Theory. 2nd ed. London: Sage, 1998. 
The Football Association Technical Department. "Football Education for Young Players: “A Charter for Quality."” London, 1997.

Vaeyens, Roel, Matthieu Lenoir, A. Mark Williams, and Renaat M. Philippaerts. "Talent Identification and Development Programmes in Sport: Current Models and Future Directions." Sports Medicine 38, no. 9 (2008): 703-14.

Vaeyens, Roel, Renaat M. Philippaerts, and Robert M. Malina. "The Relative Age Effect in Soccer: A Match-Related Perspective.” Journal of Sports Sciences 23, no. 7 (2005): 747-56. doi:10.1080/02640410400022052.

van Rossum, J., and F. Gagne. "Talent Development in Sports." In The Handbook of Secondary Gifted Education, edited by F. Dixon and S. Moon, 281-316. Waco, TX: Prufrock Press, 2005.

Williams, A. M. "Perceptual Skill in Soccer: Implications for Talent Identification and Development.” Journal of Sports Science 18, no. 9 (2000): 737-50.

Williams, A. Mark, and Tom Reilly. "Talent Identification and Development in Soccer." Journal of Sports Sciences 18, no. 9 (2000): 657-67. doi:10.1080/02640410050120041. 